\title{
Exploring drought vulnerability in Africa: an indicator based analysis to be used in early warning systems
}

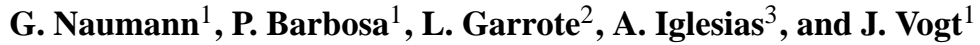 \\ ${ }^{1}$ European Commission, Joint Research Centre, 21027 Ispra (VA), Italy \\ ${ }^{2}$ Department of Civil Engineering, Universidad Politécnica de Madrid, UPM, Madrid, Spain \\ ${ }^{3}$ Department of Agricultural Economics and Social Sciences, Universidad Politécnica de Madrid, UPM, Madrid, Spain
}

Correspondence to: G. Naumann (gustavo.naumann@jrc.ec.europa.eu)

Received: 10 September 2013 - Published in Hydrol. Earth Syst. Sci. Discuss.: 8 October 2013

Revised: - Accepted: 9 March 2014 - Published: 6 May 2014

\begin{abstract}
We propose a composite drought vulnerability indicator (DVI) that reflects different aspects of drought vulnerability evaluated at Pan-African level for four components: the renewable natural capital, the economic capacity, the human and civic resources, and the infrastructure and technology. The selection of variables and weights reflects the assumption that a society with institutional capacity and coordination, as well as with mechanisms for public participation, is less vulnerable to drought; furthermore, we consider that agriculture is only one of the many sectors affected by drought.

The quality and accuracy of a composite indicator depends on the theoretical framework, on the data collection and quality, and on how the different components are aggregated. This kind of approach can lead to some degree of scepticism; to overcome this problem a sensitivity analysis was done in order to measure the degree of uncertainty associated with the construction of the composite indicator. Although the proposed drought vulnerability indicator relies on a number of theoretical assumptions and some degree of subjectivity, the sensitivity analysis showed that it is a robust indicator and hence able of representing the complex processes that lead to drought vulnerability.

According to the DVI computed at country level, the African countries classified with higher relative vulnerability are Somalia, Burundi, Niger, Ethiopia, Mali and Chad. The analysis of the renewable natural capital component at sub-basin level shows that the basins with high to moderate drought vulnerability can be subdivided into the following geographical regions: the Mediterranean coast of Africa; the Sahel region and the Horn of Africa; the Serengeti and the
\end{abstract}

Eastern Miombo woodlands in eastern Africa; the western part of the Zambezi Basin, the southeastern border of the Congo Basin, and the belt of Fynbos in the Western Cape province of South Africa.

The results of the DVI at the country level were compared with drought disaster information from the EM-DAT disaster database. Even if a cause-effect relationship cannot be established between the DVI and the drought disaster database, a good agreement is observed between the drought vulnerability maps and the number of persons affected by droughts.

These results are expected to contribute to the discussion on how to assess drought vulnerability and hopefully contribute to the development of drought early warning systems in Africa.

\section{Introduction}

Drought vulnerability is a complex concept that includes both biophysical and socio-economic drivers of drought impact that determine the capacity to cope with drought. The term vulnerability is used here to convey the characteristics of a system or social group that makes it susceptible to suffering the consequences of drought. We recognise that there is a semantic debate among some scholars on terminology and the term vulnerability may have different meanings when used in different disciplines and contexts (Smit et al., 1999; Brooks et al., 2005; Adger, 2006; Füssel, 2007); however, the concept of vulnerability used in the United Nations International Strategy for Disaster Reduction (UNISDR) refers to the internal component of risk, generally 
depicted as exposure and sensitivity (UNISDR, 2000; Adger, 2006). Drought vulnerability depends on inadequate structures and management, on limitations of technology and of the economy, or on environmental constraints. In many cases, social factors dominate (Turner et al., 2003). For example, although the direct impact of precipitation deficiencies may be a reduction of crop yields, the underlying cause of this vulnerability to meteorological drought may be that the farmers did not use drought-resistant seeds - either because they did not believe in their usefulness, their costs were too high, or because of some commitment to cultural beliefs. Another example could be farm foreclosure related to drought; the underlying cause of this vulnerability could be manifold, such as small farm size because of historical land appropriation policies, lack of credit for diversification options, farming on marginal lands, limited knowledge of possible farming options, a lack of local industry for off-farm supplemental income, or government policies.

Understanding vulnerability to drought can help to increase a region's preparedness and hence limits the greatest and most devastating effects of the hazard. Here we aim to understand the underlying causes of vulnerability, such as inadequate structures, management, and technology, or economic, environmental, and social factors, in order to provide information for a drought early warning system.

The complexity of understanding drought vulnerability hinders the development of early warning systems. Drought vulnerability is far-reaching in society - from the clear effects on hydrology (Van Loon and Van Lanen, 2012) or food production (FAO, 2010) to the less-documented effects on crime and social unrest (Burke et al., 2009; Hsiang et al., 2013). Although it is impossible to define a single measurement of drought vulnerability, it is relatively well accepted that regional disparities result as a consequence of differences in the natural capital and human and civic resources (Smit et al., 1999). However, efforts to develop vulnerability indicators have been met with a lack of agreement on the variables that may characterise this complex concept. Even in areas of high drought risk, the success of various methodological approaches to evaluate vulnerability has been mixed, reflecting the difficulty in the quantification of the concept, the multiple dimensions, and the limitations of data. To advance the understanding of drought vulnerability and support early warning systems, this paper reports a range of variables and aggregated measures of drought vulnerability. We frame this analysis in Africa, an area where drought risk is a major issue, where most climate scenarios project further water limitations (Christensen et al., 2007), where water sustains food production and exceptionally high biodiversity areas, and where the effect of drought on human displacement and potential violent conflict is a reality (Westing, 1992).

Traditionally, an indicator approach uses different types of scales and factor analyses to investigate social, economic and environmental factors (Smit et al., 1999; Leichenko and O'Brien, 2002). In most of these studies, variables are se- lected based on the attribute to be represented and the availability of data. Thus an analyst may find it rather easy to propose types of indicators which do not refer to a particular case and whose evaluations results may differ enormously from reality. However, presenting a real case would avoid this problem, and analysing the main reasons and causes of these answers would be much easier for the researcher.

Drought in Africa has generated widespread media attention. The debate on anticipatory drought early warning systems and drought relief assistance has been at the centre of the United Nation International Strategy for Disaster Reduction since the early 2000s (UNISDR, 2000). Moreover, with a growing population, society is becoming increasingly concerned and stronger worries are placed on the effects of drought on water, food and health security. Thus, the increasing social awareness about the effects of drought on people combined with adverse climate change predictions exacerbates the situation.

Given the complexity of drought vulnerability, it is essential to incorporate the different determinants of the drought response, including social, economic and environmental aspects (Smit et al., 1999). A good example of this intention is the evaluation of drought vulnerability in Australia, which represents a benchmark in the design of drought policy and greatly promotes stakeholder and public participation in decision- and policy-making processes (Nelson et al., 2008).

Studies that analyse the reasons behind drought vulnerability have been less numerous than those dealing with the physical event. There are a number of studies which assess drought vulnerability on large geographical areas based on drought indices (Charusombat and Niyogi, 2011; VicenteSerrano et al., 2012; Taylor et al., 2013; Van Lanen et al., 2013) and others which highlight the factors that influence local populations and livelihoods (Wilhelmi and Wilhite, 2002; Luers et al., 2003; Shiau and Hsiao, 2012.).

We contribute to an understanding of drought vulnerability in Africa, recognising its multiple components and limitations to express many social and environmental attributes in a common scale across the continent. Although there are a number of studies focusing on local case evaluations of vulnerability (Eriksen et al., 2005; Eriksen and O'Brien, 2007; Anderson et al., 2012; van Huijgevoort et al., 2012; Welsh et al., 2013), the majority of the studies focuses mainly on the hazards, due in large part to the difficulty in finding appropriate social indicators.

Building and validating a composite vulnerability indicator can be extremely difficult. In particular, the impact of data perturbation, such as adding or deleting a variable and the weighting scheme adopted, should be the main concerns when building the composite indicator. However, these issues are infrequently addressed in the literature (Cherchye et al., 2008; Saisana et al., 2005).

During the construction process of the composite indicator it is desirable to account for the sources of uncertainty, while the inference process should be as objective and simple as 
possible (Nardo et al., 2005). Here we propose an analysis divided into three main parts that are essential to any vulnerability assessment approach: (i) definition of the components of drought vulnerability, (ii) selection of variables and their normalisation, and (iii) model validation through a weighting and sensitivity analysis, and comparison with other indicators. A detailed analysis on the weighting scheme adopted as well as a comparison with the impacts of previous drought disasters may help in the stakeholders' acceptance of the indicator.

Advances in seasonal forecast skill (Dutra et al., 2013, 2014) open the possibility for improved drought early warning systems. However, the implementation of such systems also requires an understanding of the social capacity to use the forecast. Here we propose a methodology to characterise drought vulnerability and apply the methodology in Africa.

\section{Methods and data}

\subsection{Framework}

The study includes three steps aiming to provide a transparent construction of the composite index of drought vulnerability and assist in the interpretation of the results (Fig. 1). The first is the definition of the determinants of drought vulnerability, which includes a theoretical framework providing the basis for the selection and combination of the different components. The components included represent the social, economic and environmental aspects of sustainability. In addition, we have considered explicitly the technology and infrastructure that are directly relevant to drought vulnerability in agriculture and water resources management.

The second methodological step is the selection of variables that define each component of drought vulnerability. We have based this selection on two criteria: the variable has to represent a quantitative or qualitative aspect of drought vulnerability, and public data need to be available, in this case FAO, World Bank, UN, and the data sets of Vörösmarty et al. (2000) that are available in the Water Systems Analysis Group of the University of New Hampshire. This emphasis on public databases ensures that the final result can be validated, reproduced and improved with new data by stakeholders. In order to include the variables in a composite index, they have to be normalised with respect to some common baseline. In this case the baseline is defined by the sample of all African countries. Therefore, the values of the resulting indicators can only be interpreted and compared within the African continent.

Finally, the development of a drought vulnerability index is validated through a series of steps: weighting and aggregation, analysis of sensitivity of the inclusion or exclusion of variables, and comparison with information on past drought disasters.

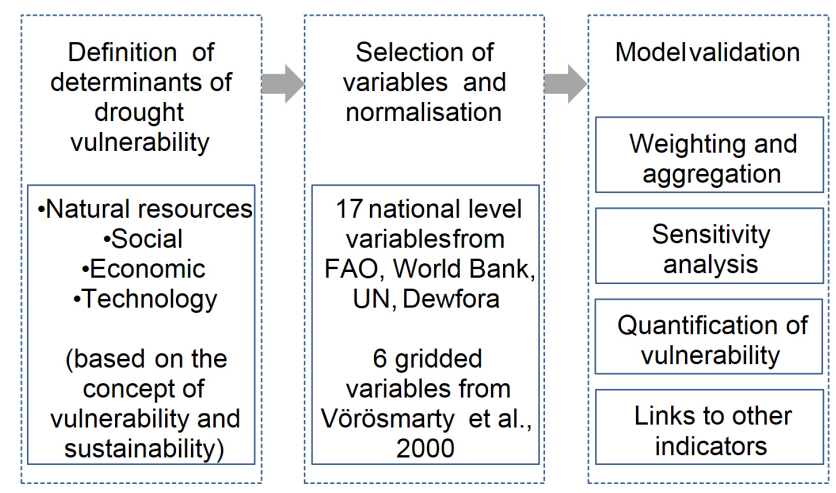

Fig. 1. Summary of the methodological framework.

\subsection{Definition of determinants of the drought vulnerability indicator (DVI)}

In order to assess the drought vulnerability and then the risk for a certain region, the definition of vulnerability to drought should reflect the complex interactions between the socioeconomic systems and the physical environment. Defining vulnerability to drought is complex and involves some measure of susceptibility, exposure, coping capacity and adaptive capacity (Birkmann, 2007; Iglesias et al., 2009).

The multidimensional concept of vulnerability can be divided into different subgroups (components). These components can be dependent and linkages between them can exist. Within the framework of this work the drought vulnerability index is expressed as a function of four components that address different aspects of vulnerability: renewable natural capital, economic capacity, human and civic resources, and infrastructure and technology. The definition of the components was based on the relevance of each indicator for policy development and the entire statistical structure of the data set. An analytical approach was then used to explore whether the components are statistically well balanced in the composite indicator.

For each component a normalisation scheme was necessary prior to data aggregation, as most of the single indicators have different measurement units. Each component is assessed as a geometric mean of a set of indicators inferred from variables that can be obtained in public databases and therefore contrasted by stakeholders. The scores of the DVI range on a scale of 0 to 1 , where 0 represents the lowest vulnerability and 1 is associated with the highest vulnerability.

The socio-economic vulnerability components and the related variables were selected on the basis that: (1) data is readily available and an example may be computed to assist stakeholders in defining the sensitivity of the system; and (2) the variables are drought scenario dependent and geographically explicit. The vulnerability indicator may be used to understand the fragility of the system and to assist in the selection of measures to be adopted. For example, improving 
the efficiency of agricultural water use, decreasing population under the poverty line, increasing the adult literacy rate, and increasing agricultural technology, are measures that result in an overall vulnerability decrease.

\subsection{Selection of variables and relevance}

The variables that have been used to characterise the four components of socio-economic vulnerability were compiled for the 53 African countries from the sources listed in Table 1 . In order to be used for the computation of the DVI, each variable must have at least $75 \%$ of the countries without missing data. A final sub-indicator for each of the four components may be computed as the weighted average of all the representative variables within the component.

From the 17 variables selected, the amount of absent data for each indicator ranged between 0 and $17 \%$. For the variables that present missing values according to the main source (see Table 1) the values were completed from secondary sources. This is the case for the energy use, GDP per capita and fertiliser consumption and population below the poverty line.

However, not all the values could be completed using secondary sources. Although several approaches and guidelines on data treatment for missing values can be used (Little and Rubin, 2002; Nardo et al., 2005) we chose an unconditional imputation due to the existence of only a few missing values, simplicity, and reproducibility of the experiment by stakeholders. The remaining missing data -19 from a total of 901 values presented in Table 2 - were filled by explicit modelling using an unconditional median imputation of each indicator in the entire data set (Nardo et al., 2005). The interpretation of the DVI results for those countries where the median was used should be done carefully.

The drought vulnerability index is a composite indicator calculated by weighted aggregation of 17 variables that represent the four components. The selection of the variables included followed two criteria: they represent the concept to be explored and are publicly available. This vulnerability index may be used to understand the sensitivity of the system and to assist in the selection of measures to be adopted.

Due to the limitations of data, the DVI computation was only done at the country level, while the analysis of the renewable natural capital component of the DVI was also carried out at the grid level $(1 \times 1$ degrees $)$. Although drought impacts are generated by local processes and conditions, a national level analysis seems appropriate to be used by central governments and international organisations in the determination of drought policies.

The five variables selected for the renewable natural capital component were: agricultural water use, total water use, precipitation, irrigated area, and population density. These variables are relevant to assess drought vulnerability. Agricultural water use - the amount of water used for agriculture as the percentage of the total water used in the country - is a measure of the dependence of the agricultural sector on water availability. Total water use - total freshwater withdrawn in a given year expressed in percentage of the actual total renewable water resources - is an indication of the pressure on the renewable water resources. Average precipitation relates to the dependency of the country on the aridity level and therefore the need for regulation of water sources. The irrigated area - as a share of total agricultural area - directly lowers vulnerability to meteorological drought; however, mismanagement of irrigation allocation may result in increased or urban and ecosystems vulnerability. Finally, the population density is an indicator of the human pressure on water resources and hence a higher density increases drought vulnerability.

This component was also characterised at higher resolution (all variables were aggregated to a common resolution of $1 \times 1$ degree grid) by using similar corresponding variables available from the University of New Hampshire data sets (Vörösmarty et al., 2000). From the variables available in this digital archive the following variables were selected to obtain an index equivalent to the renewable natural capital: irrigation-equipped area, irrigation water withdrawals, agricultural area, rural population and total population. Gridded normal precipitation form the Global Precipitation Climatology Centre data set (Schneider et al., 2013) was also used. It is clear that the higher resolution is preferred in order to characterise local disparities within countries. The indicators at the finer resolution level were then aggregated in the study at the sub-basin level which can be of use for water basin management.

The four variables included to characterise the economic capacity component of the drought vulnerability index were: GDP per capita, agricultural value added, energy use, and population living below poverty line. The relevance of these variables for assessing drought vulnerability is as follows. GDP per capita - the total economic output of a country divided by the number of people in the country - while an imperfect measure of well-being, is widely used in sustainability and human development indicators as the main variable affecting the country's economic capacity, and directly correlated to lower vulnerability. Agricultural value added per unit of GDP is associated with the manufacturing processes that increase the value of primary agricultural production and is directly correlated to lower vulnerability. The energy use use of primary energy before transformation to other end-use fuels - reflects economic capacity and therefore also correlates positively with a lower vulnerability potential. In contrast, population living below poverty line - with purchasing power parity below $\$ 1.25 /$ day - correlates with higher vulnerability levels since poverty influences the capacity to cope and respond to drought impacts.

The selection of variables to characterise human and civic resources is more controversial and data are less readily available. Here we have selected six variables that have been widely used in previous studies. Adult literacy rate, life 
Table 1. Vulnerability factors and their related weights included in the DVI.

\begin{tabular}{|c|c|c|c|}
\hline Component & $\begin{array}{l}\text { Aspect relevant to } \\
\text { drought management } \\
\text { and type of influence }\end{array}$ & Indicator & Data source \\
\hline \multirow{5}{*}{$\begin{array}{l}\text { 1. Renewable } \\
\text { natural capital }\end{array}$} & $\begin{array}{l}\text { Water management, } \\
\text { positive influence }\end{array}$ & $\begin{array}{l}\text { Agricultural water use ( } \% \text { of total) } \\
\text { Irrigation water withdrawals } \\
\text { (millions of } \mathrm{m}^{3} \text { year }^{-1} \text { per grid cell) }\end{array}$ & $\begin{array}{l}\text { Aquastat } \\
\text { World Water Assessment Program, } \\
\text { World Water Development Report II. } \\
\text { http://wwdrii.sr.unh.edu/index.html }\end{array}$ \\
\hline & Water management & Total water use ( $\%$ of renewable) & FAO, Aquastat; CRU \\
\hline & Water management & $\begin{array}{l}\text { Irrigated area (\% of cropland) } \\
\text { Irrigation-equipped area }\left(\mathrm{km}^{2} \text { per grid cell) }\right. \\
\text { Agricultural area }\left(\mathrm{km}^{2}\right) \\
\text { Rural population, year } 2000 \text { (people per grid } \\
\text { cell) and Total population, year } 2000 \\
\text { (people per grid cell) }\end{array}$ & $\begin{array}{l}\text { Aquastat } \\
\text { World Water Assessment Program, World } \\
\text { Water Development Report II. } \\
\text { http://wwdrii.sr.unh.edu/index.html }\end{array}$ \\
\hline & Water availability & 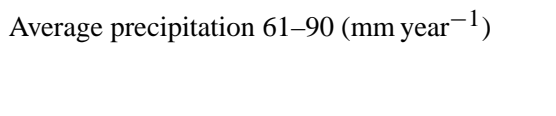 & $\begin{array}{l}\text { Aquastat } \\
\text { GPCC (Global Precipitation Climatology } \\
\text { Centre, DWD) }\end{array}$ \\
\hline & Pressure on resources & Population density (inhab km² ${ }^{-2}$ ) & $\begin{array}{l}\text { Aquastat, } \\
\text { World Water Assessment Program, World } \\
\text { Water Development Report II. }\end{array}$ \\
\hline \multirow{4}{*}{$\begin{array}{l}\text { 2. Economic } \\
\text { capacity }\end{array}$} & Economic welfare & GDP per capita USD & $\begin{array}{l}\text { UNDP Human Development Index } \\
\text { World Statistics Pocketbook } \\
\text { (United Nations Statistics Division) }\end{array}$ \\
\hline & Food security & Agricultural value added/GDP \% & Aquastat \\
\hline & Economic welfare & Energy use (kg oil equivalent per capita) & $\begin{array}{l}\text { World Bank } \\
\text { World Statistics Pocketbook } \\
\text { (United Nations Statistics Division) }\end{array}$ \\
\hline & Collective capacity & $\begin{array}{l}\text { Population living below USD } 1.25 \text { PPP per day } \\
(\%)\end{array}$ & UNDP Human Development Index \\
\hline \multirow{6}{*}{$\begin{array}{l}\text { 3. Human and } \\
\text { civic resources }\end{array}$} & $\begin{array}{l}\text { Human development } \\
\text { (individual level) }\end{array}$ & Adult literacy rate $(\%)$ & UNDP Human Development Index \\
\hline & $\begin{array}{l}\text { Human development } \\
\text { (individual level) }\end{array}$ & Life expectancy at birth (years) & UNDP Human Development Index \\
\hline & $\begin{array}{l}\text { Collective capacity, } \\
\text { institutional coordination }\end{array}$ & $\begin{array}{l}\text { Government Effectiveness (ranges from } \\
\text { approximately }-2.5 \text { (weak) to } 2.5 \text { (strong) } \\
\text { governance performance) }\end{array}$ & World bank \\
\hline & $\begin{array}{l}\text { Collective capacity, } \\
\text { institutional coordination }\end{array}$ & Institutional capacity ( 0 to 1 ) & DEWFORA \\
\hline & Collective capacity & $\begin{array}{l}\text { Population without access to improved } \\
\text { water }(\%)\end{array}$ & World Bank \\
\hline & Human displacement & Refugees (\% of total population) & UNHCR \\
\hline \multirow[t]{2}{*}{$\begin{array}{l}\text { 4. Infrastructure } \\
\text { and technology }\end{array}$} & Development & $\begin{array}{l}\text { Fertiliser consumption } \\
\text { (kilograms per hectare of arable land) }\end{array}$ & $\begin{array}{l}\text { World Bank, Fertiliser consumption total in } \\
\text { Tons from Faostat, Arable land in Kha from } \\
\text { Aquastat }\end{array}$ \\
\hline & $\begin{array}{l}\text { Water management } \\
\text { potential }\end{array}$ & $\begin{array}{l}\text { Water infrastructure } \\
\text { (storage as proportion of total RWR) }\end{array}$ & Aquastat \\
\hline
\end{tabular}


Table 2. Table of missing data per country and indicator. Only countries and indicators with missing data are shown.

\begin{tabular}{|c|c|c|c|c|c|c|c|c|c|c|c|c|c|c|c|}
\hline 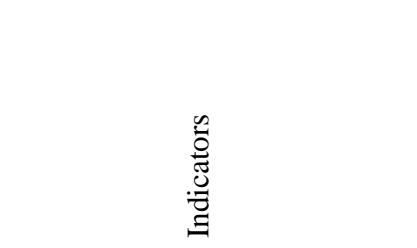 & $\frac{\stackrel{\pi}{\bar{D}}}{\mathbb{E}}$ & 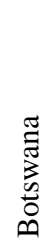 & 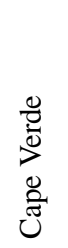 & 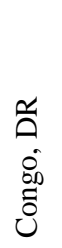 & $\begin{array}{l}\ddot{\Xi} \\
: 0 \\
: 0 \\
0\end{array}$ & 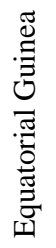 & 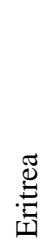 & 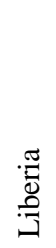 & $\stackrel{\pi}{\frac{\pi}{2}}$ & $\begin{array}{l}. \stackrel{\Xi}{\Xi} \\
\stackrel{\Xi}{\Xi} \\
\Sigma\end{array}$ & 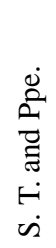 & 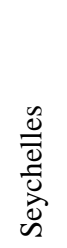 & $\begin{array}{l}\stackrel{\widetilde{\Xi}}{\widetilde{\Xi}} \\
\stackrel{\Xi}{\Xi} \\
\mathscr{n}\end{array}$ & 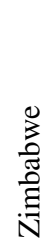 & $\stackrel{\varpi ّ}{0}$ \\
\hline Total water use & & & & & & & & & & & 1 & 1 & & & 2 \\
\hline Population living below poverty & 1 & 1 & & & & 1 & 1 & & 1 & 1 & 1 & & 1 & 1 & 9 \\
\hline Adult literacy rate & & & & 1 & 1 & & & & & & & & & & 2 \\
\hline $\begin{array}{l}\text { Population without access } \\
\text { to improved water }\end{array}$ & & & & & & & & & 1 & & & & & & 1 \\
\hline Fertiliser consumption & & & & & 1 & 1 & & 1 & & & 1 & & & & 4 \\
\hline Water infrastructure & & & & & & & & & & & & 1 & & & 1 \\
\hline Total & 1 & 1 & 1 & 1 & 2 & 2 & 1 & 1 & 2 & 1 & 3 & 2 & 1 & 1 & 19 \\
\hline
\end{tabular}

expectancy at birth, and population without access to improved water are included in the Human Development Index (HDI) of the United Nations. In addition, we have considered institutional capacity and government effectiveness, to represent the management dimensions of drought vulnerability. Finally, we included a measure of the displaced population and refugees, since this is an important factor that reduces the coping capacity of population to drought. The relevance of these variables for assessing drought vulnerability is summarised below.

Institutional capacity refers to the capacity of a country to cope with drought events; a higher institutional capacity implies lower drought vulnerability. Government effectiveness reflects perceptions of the quality of public services, the quality of the civil service and the degree of its independence from political pressures, the quality of policy formulation and implementation, and the credibility of the government's commitment to such policies. Adult literacy rate refers to the percentage of the population aged 15 and older who can, with understanding, both read and write a short simple statement on their everyday life. A higher literacy rate implies a higher capacity to deal with drought events. Life expectancy at birth can be related to a population's vulnerability to extreme events, including drought, because the lack of sufficiently elderly people will prevent appropriate traditional knowledge transmission to young generations. Population without access to improved water (percentage of the population with reasonable access to an adequate amount of water from an improved source) is the most widely used indicator of drought damage in the most vulnerable areas and has been a subject of the Millennium Development Goals. Reasonable access is defined as the availability of at least 20 litres per person a day from a source within one kilome- tre of the dwelling; greater access to improved water reduces drought vulnerability. The number of refugees and displaced population (as defined by the UNHCR) increases drought vulnerability of the country, since a refugee population is more likely to be exposed to natural hazards and less capable of coping with disasters.

The two variables selected for the infrastructure and technology component were fertiliser consumption, and water infrastructure. Fertiliser consumption is a widely accepted measure of agricultural technology, and it is included as an indicator in most rural development studies. Water infrastructure measures the water stored as proportion of total renewable water resources and reduces the vulnerability to drought.

\subsection{Normalisation of variables to a common baseline}

The variables in Table 1 were normalised between the different countries in order to be able to directly compare results. The normalisation has been made taking into account the maximum and minimum value of each variable across all countries in order to combine variables within the categories and to guarantee that variables have an identical range between 0 and 1 .

For variables with a positive correlation to the overall vulnerability, the normalised value is then calculated according to the general linear transformation, with

$Z_{i}=\frac{X_{i}-X_{\min }}{X_{\max }-X_{\min }}$.

Here $X_{i}$ represents the variable value for a generic country $i$, $X_{\min }$ and $X_{\max }$ the respective minimum and maximum value across all countries $i$.

In some cases there is an inverse relationship between vulnerability and adaptive indicators (e.g. GDP per capita, adult 
literacy rate, or water infrastructure). For variables with negative correlation to the overall vulnerability, a transformation was applied to link the lowest variable values with the highest values of vulnerability:

$Z_{i}=1-\left(\frac{X_{i}-X_{\min }}{X_{\max }-X_{\min }}\right)$.

In this way all normalised indicators $\left(Z_{i}\right)$ have values between 0 (less vulnerable) and 1 (most vulnerable). Then, for each country, any of the $k(k=1, \ldots, 4)$ components $(C)$ are computed as the arithmetic mean of the variables $Z_{i}$ that define each component.

$$
C_{k}=\frac{1}{n} \sum_{k=1}^{n} Z_{k}
$$

\subsection{Quantification of the drought vulnerability indicator (DVI)}

The DVI is calculated with a similar methodology as the Human Development Indicator (Neumayer, 2001), where each component of the DVI can be viewed as a dimension. In this way the DVI can be used as a guide to policies but also can be decomposed in order to measure the individual impact of each component and extend the analysis of country performance.

Sub-component variables can be combined within each category by using either a geometric mean or a weighted mean with weights inversely proportional to the impact uncertainty level. This study considers the weights separately for each of the categories, as in Iglesias et al. (2007), in order to evaluate them independently. This allows evaluation of the strengths and weaknesses of each component of the total vulnerability index within each country. It should be pointed out that the vulnerability components have an inverse interpretation to the adaptation capacity components.

The overall drought vulnerability index is then calculated for each country as a weighted aggregation of the components as

$\mathrm{DVI}_{i}=\sum_{k=1}^{4} W_{k} C_{i, k}$

where $W_{k}$ are the weights assigned for the $k$ component (with $\left.\Sigma w_{k}=1\right)$ and $C_{i, k}$ are the components for each country. The DVI gives the relative vulnerability of a country with respect to all the countries considered in the computation.

\subsection{Weighting and aggregation}

The selection of the weighting scheme is related with the relative importance of each component of the DVI. The weights selected can affect the value of the DVI and then the final ranking of each country. Since no perfect weighting and aggregation convention exists (Arrow, 1963) it is necessary to test the stability and robustness of the weighting scheme selected.

The influence of weighting on the DVI was tested using three different weighting schemes: equal weights (EW), a weighting scheme according the number of variables in each component (proportional weights, PW) and random weights (Montecarlo with 1000 simulations, RW).

The construction of the components can be made by expert opinion or by analysing the statistical structure of the data set. Different analytical approaches, such as cluster analysis or principal component or factor analysis can be made to test if the dimensions defined theoretically are well balanced (Nardo et al., 2005). In this step, the four components defined in Table 1 were compared against a new set of four dimensions obtained after an objective classification ( $k$ means clustering; Hartigan and Wong, 1979) of all the indicators. This is a purely statistical method of aggregation of indicators and is useful for exploring the impact of the methodological choices during the development of the components.

\subsection{Sensitivity analysis of the indicator}

Uncertainty analysis focuses on how uncertainty in the input factors (variables included, weighting, and aggregation) propagates through the overall structure of the DVI composite indicator. A sensitivity analysis was undertaken in order to assess the robustness of the DVI. This examination is conducted as different Monte Carlo experiments to assess the contribution of any individual source of uncertainty to the output variance. This methodology is based on multiple evaluations of the model with three weighting and two aggregation schemes that generate different probabilistic density functions (PDF) of model outputs.

The main decisions tested were (1) inclusion or exclusion of variables for the different weighting schemes (PW, EW, and RW); and (2) variables aggregation in the four components according to the theoretical framework and according to cluster analysis.

The stability of the DVI and of the rank assigned by the composite indicator to a given country $\left(\operatorname{Rank}\left(\mathrm{DVI}_{i}\right)\right)$ is an indicator of the robustness of the estimation. The shift in country rankings $R_{\mathrm{S}}$ is hence a measure of the uncertainty of each input factor. The mean value of $R_{\mathrm{S}}$ can be computed as the differences in countries' ranks in respect to the reference ranking over the total number of countries $(C)$ :

$\overline{R_{\mathrm{S}}}=\frac{1}{C} \sum_{i=1}^{C}\left(\operatorname{Rank}\left(\mathrm{DVI}_{i(\mathrm{ref})}\right)-\operatorname{Rank}\left(\mathrm{DVI}_{i}\right)\right)$,

where the reference ranking is given by the theoretical framework aggregation using proportional weights.

The uncertainties from the input factors are then expressed as the resulting PDFs of the DVI, $\operatorname{Rank}\left(\mathrm{DVI}_{i}\right)$ and $R_{\mathrm{S}}$. The uncertainty bounds associated to the DVI values are also useful to communicate to the end users all the plausible values that the DVI can reach for each country. Finally, a sensitivity 


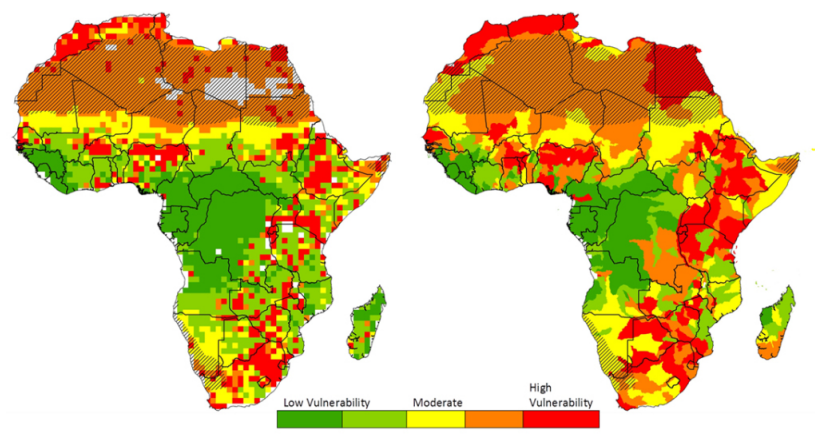

Fig. 2. (a) Renewable natural component of drought vulnerability at pixel level, and (b) renewable natural component of drought vulnerability at sub-basin level. Areas with annual precipitation below $150 \mathrm{~mm}$ year $^{-1}$ were masked (shaded region).

analysis can help to increase the transparency and to identify which countries are favoured or weakened under the different assumptions.

\subsection{Comparison of the DVI with drought disaster observations}

In order to assess how the vulnerability indicators are correlated with drought disasters, the tetrachoric correlation (Drasgow, 1986) was computed between the DVI and the numbers of persons reported affected (PRA) by drought disasters retrieved from the EM-DAT data set (The OFDA/CRED International Disaster Database - www.emdat. be, Université Catholique de Louvain, Brussels (Belgium)). EM-DAT is a global database on natural and technological disasters that contains data on the occurrence and effects of natural disasters in the world from 1900 to present. The DVI and PRA variables were converted to dichotomous variables by using their median threshold to define two categories (low and high DVI; low and high PRA). After the dichotomisation a tetrachoric test was carried out to determine whether there is a significant agreement between the two variables.

\section{Results}

The analysis of the results referring to the methodology presented before is divided into three sections. The first section presents a simplified agricultural drought vulnerability index that takes in account only the renewable natural capital variables that were available at $1 \times 1$ degree resolution. The second section presents the final results of the DVI at national level after performing an appropriate weighting and aggregation scheme as well as a sensitivity analysis study. Finally, the third section compares the DVI results with a historical database of drought disasters.
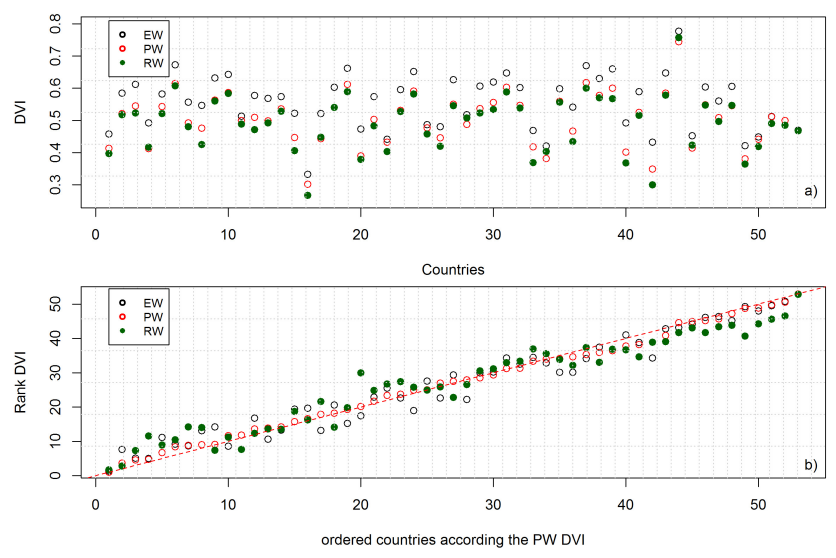

Fig. 3. (a) DVI values and (b) ranking of each country according with the average value of DVI computed with equal weights (EW), proportional weights $(\mathrm{PW})$ and random weights (RW).

\subsection{Renewable natural capital component of drought vulnerability at pixel level}

The renewable natural capital component of vulnerability of agricultural systems in Africa at pixel level was assessed by using the global gridded data set reported by Vörösmarty et al. (2000). A recent study in Africa (Vörösmarty et al., 2005) demonstrates the utility of such geospatial data sets in a wide range of indicator applications in areas with scarce local data. Figure 2a shows the natural capital component of drought vulnerability of agricultural systems. The areas of higher vulnerability correspond with the areas of high density of crops and population as depicted in Vörösmarty et al. (2000). Those areas include the Mediterranean climates of Africa, the Sahel and almost the entire eastern part of the continent, including the Greater Horn of Africa (GHA).

A regional vulnerability analysis was performed by aggregating the data at sub-basin level (Fig. 2b). The most vulnerable sub-basins (high to moderate in Fig. 2) can be grouped into three main different regions: (1) the Mediterranean coast of Africa, comprising most of the Moroccan and Algerian basins and the Nile Delta; (2) the Sub-Sahara and the southern Sahel regions of the Volta and Niger, White and Blue Nile and the Horn of Africa; (3) the Serengeti and the Eastern Miombo woodlands in Tanzania and Mozambique and the Limpopo. A few local spots of high vulnerability can be added to these regions: the eastern part of the Zambezi River and the southeastern border of the Congo Basin, and the belt of Fynbos (natural shrub land vegetation) in the Western Cape of South Africa.

\subsection{Drought vulnerability indicator at national level}

\subsubsection{Weighting and aggregation}

The first analysis was performed by excluding one of the 17 variables each time, taking into account the three weighting 


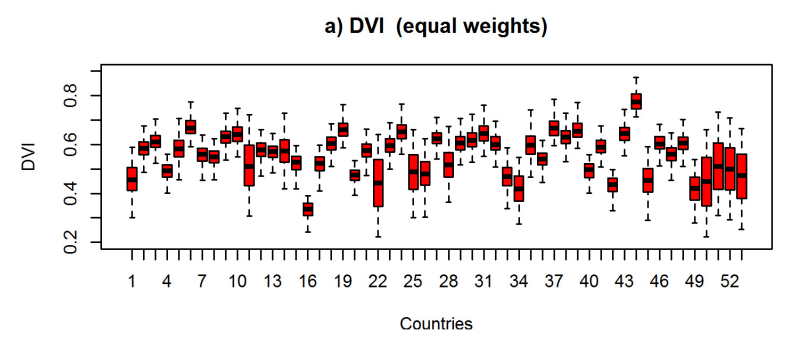

c) DVI (proportional weights)

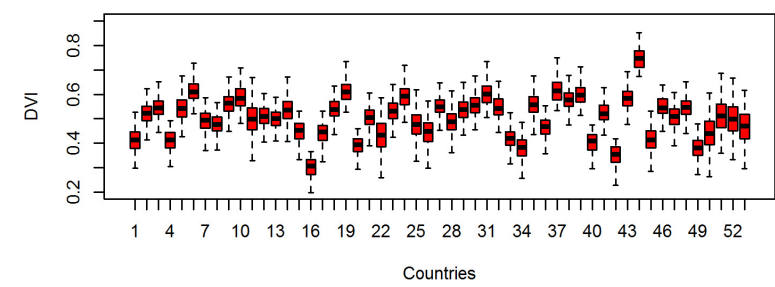

e) DVI (Random Weights)

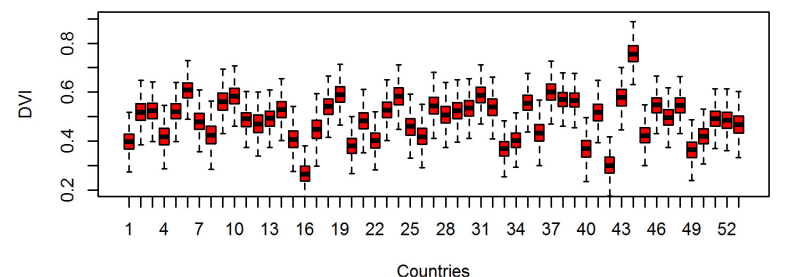

b) Rank DVI (equal weights)

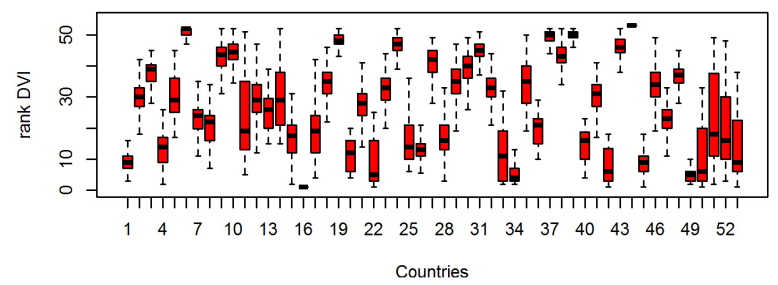

d) Rank DVI (proportional weights)

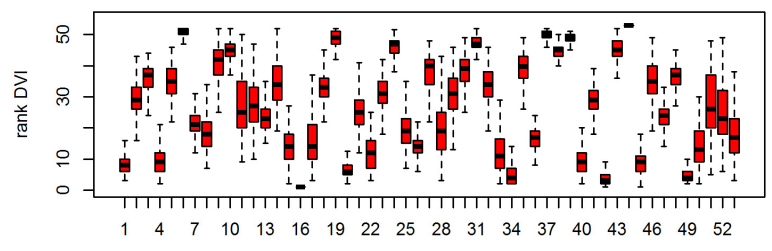

Countries

f) Rank DVI (Random weights)

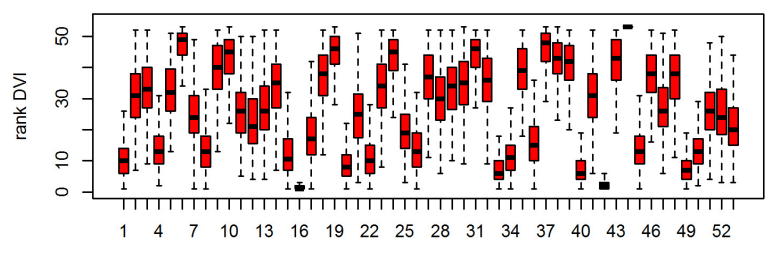

Countries

Fig. 4. Summary of the estimated DVI values (left) and their related country ranking (right) for the three weighting schemes (a, b: equal weights, $\mathbf{c}, \mathbf{d}$ : proportional weights and e, f: random weights). Dashed lines extend from 5th to 95th percentile of estimations, boxes extend from 25 th to 75 th percentile and middle horizontal lines within each box indicate the median for each country. The countries were numbered following their alphabetical order (see Fig. 7 for the corresponding names).

schemes (EW, PW, and RW). In the case of the RW scheme, since there were no a priori weights, 1000 repetitions were done for each variable exclusion in order to compute the DVI.

Figure 3 shows the values of the average DVI and ranking obtained for all countries using the three different weighting schemes. The results show that, for most countries, there is little dispersion for the DVI values obtained with the three weighting schemes. The DVI ranges between 0.25 and 0.75 and most of the countries are between 0.4 and 0.6 for all the estimations. The equal weights scheme produces the largest dispersion of values and tends to be higher than the other estimations for most countries.

If the country ranks are compared, taking as reference the estimation using proportional weights, no systematic differences are observed, while most of the countries remain in the same quintile. However, those countries ranked in the borders of the five DVI categories (low to high vulnerability) are more likely to be misclassified. Furthermore, the most extreme categories (low and high vulnerability) present the highest number of countries that can be classified in the adjacent category.

\subsubsection{Sensitivity analysis}

The sensitivity of the DVI to the inclusion or exclusion of one of the 17 variables was assessed for the three weighting schemes. As a result, DVI value scores were obtained as nonlinear functions of the uncertain input factors and their PDF reflect the overall uncertainty.

Figure 4 shows the box plots of each country DVI value and rank for the three weighting schemes. The results show larger dispersion for DVI and rank values for the equal weights option, while the test with random weights shows a low dispersion in DVI values but a high dispersion in the country ranks. These results are suggesting that the proportional weights option is more robust with respect to missing data.

A further comparison between equal weights and proportional weights options is presented in Fig. 5a and b. The plot on the right (Fig. 5b) shows DVI values computed with proportional weights versus DVI values computed with equal and random weights. There is a good correlation between results obtained with both methods. DVI values computed with proportional weights are generally smaller than DVI values computed with equal weights and larger than DVI values computed with random weights. The plot on the left (Fig. 5a) 

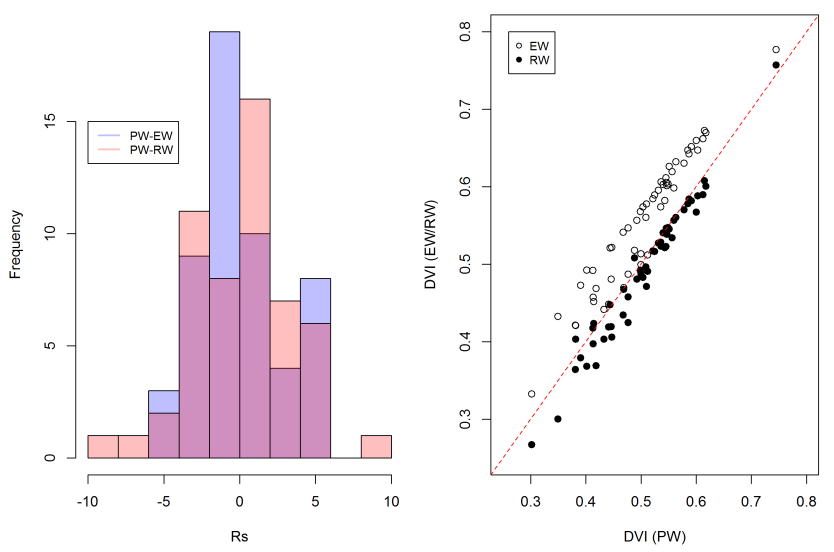

Fig. 5. (a) Difference of country rankings $\left(R_{\mathrm{S}}\right)$ considering the proportional weights $(\mathrm{PW})$ compared with equal (EW, in blue) and random (RW, in pink) weights. (b) Scatterplot of DVI values considering the proportional weights (PW) compared with equal (EW) and random (RW) weights.

shows the histogram of differences in rankings of countries between DVI computed with proportional weights and the two other schemes (EW and RW). The standard deviation of rank differential is 3.3 for $\mathrm{EW}$ and 2.7 for RW, while the mean was around 0 for all the schemes. It can be concluded that the rank difference in $69 \%$ of the countries belongs to the interval $[-3,3]$, confirming a low dispersion in the estimation of DVI rank values.

The definition of the components, even if they are defined within a theoretical framework, can be another source of uncertainty. The construction of the components can be tested to see if they are well balanced and produce a robust composite indicator. Cluster analysis can be used as an objective tool for classifying the original indicators into components. This methodology gives a purely statistical method of aggregation of indicators and can be used to measure the impact of methodological choices during the construction of the components.

Figure 6a shows the histogram of differences in country rankings according to DVI computed using the theoretical framework components, and the four components obtained after the clustering (both with PW). The standard deviation here is around 4.0, meaning that most of the countries can vary their rank in 4 or less positions. Figure $6 \mathrm{~b}$ shows that the cluster scheme tends to underestimate the DVI values systematically as compared with the theoretical framework scheme.

Overall, the proportional weights option produces intermediate results with the lowest dispersion in most countries (Fig. 4), adding value over the random weights scheme and reducing the extreme behaviour of the equal weights scheme. Furthermore, the comparison of the theoretical framework scheme was not substantially different from the cluster scheme (Fig. 6). This means that the DVI computed with
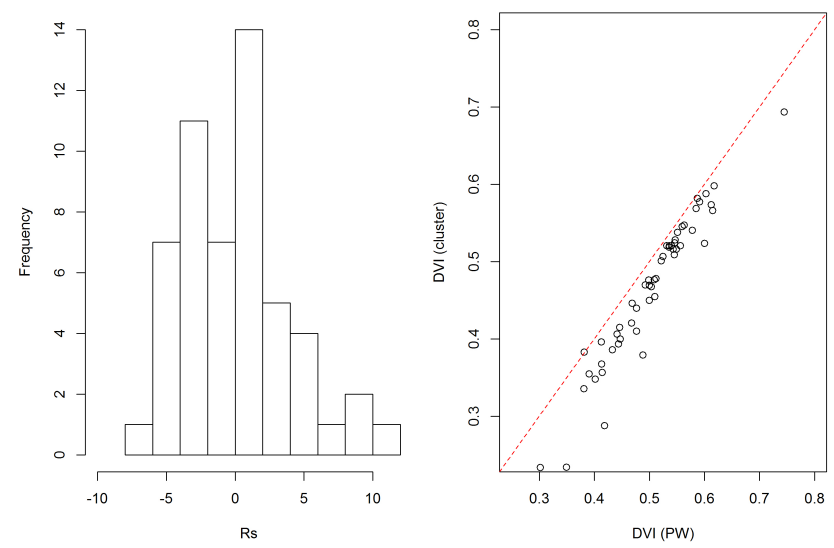

Fig. 6. (a) Histogram of the difference of country rankings according to DVI computed using the theoretical framework components and the four components obtained after the clustering (both with PW); and (b) Scatterplot of DVI values according to the theoretical framework components and the four components obtained after the clustering (both with PW).

the theoretical framework scheme and proportional weights gives an unbiased representation of overall vulnerability, and hence this was the DVI selected for further analysis.

\subsubsection{Analysis of the DVI}

The DVI for each country, including the value of its four components, is shown on Fig. 7, while the DVI map is presented in Fig. 8. The scores of the vulnerability index range on a scale from 0 to 1 , with 0 the least vulnerable and 1 the most vulnerable.

According to this analysis, the six countries with the highest vulnerability are Somalia, Burundi, Niger, Mali, Ethiopia and Chad, with DVI values close to or higher than 0.6. In order to understand the source of vulnerability in each case it is useful to analyse each dimension and sub-index separately. For example, according to Fig. 9 Mali shows high vulnerability in renewable natural capital and human and civic resources, while Ethiopia and Somalia are vulnerable in the four sub-categories. Libya is the country with highest score in renewable natural capital vulnerability, Liberia in economic capacity, Somalia in human and civil resources and Seychelles in infrastructure and technology.

\subsection{Comparing drought vulnerability estimates with observed data}

The results of the DVI were compared with drought disasters information contained in the EM-DAT database using the PRA variable. In this database, countries like Sudan, Ethiopia, Mozambique, and Niger reported more than 10 million people affected by droughts in the period 1970-2006. All those countries are classified as highly vulnerable to drought according to the DVI. Moreover, countries that 


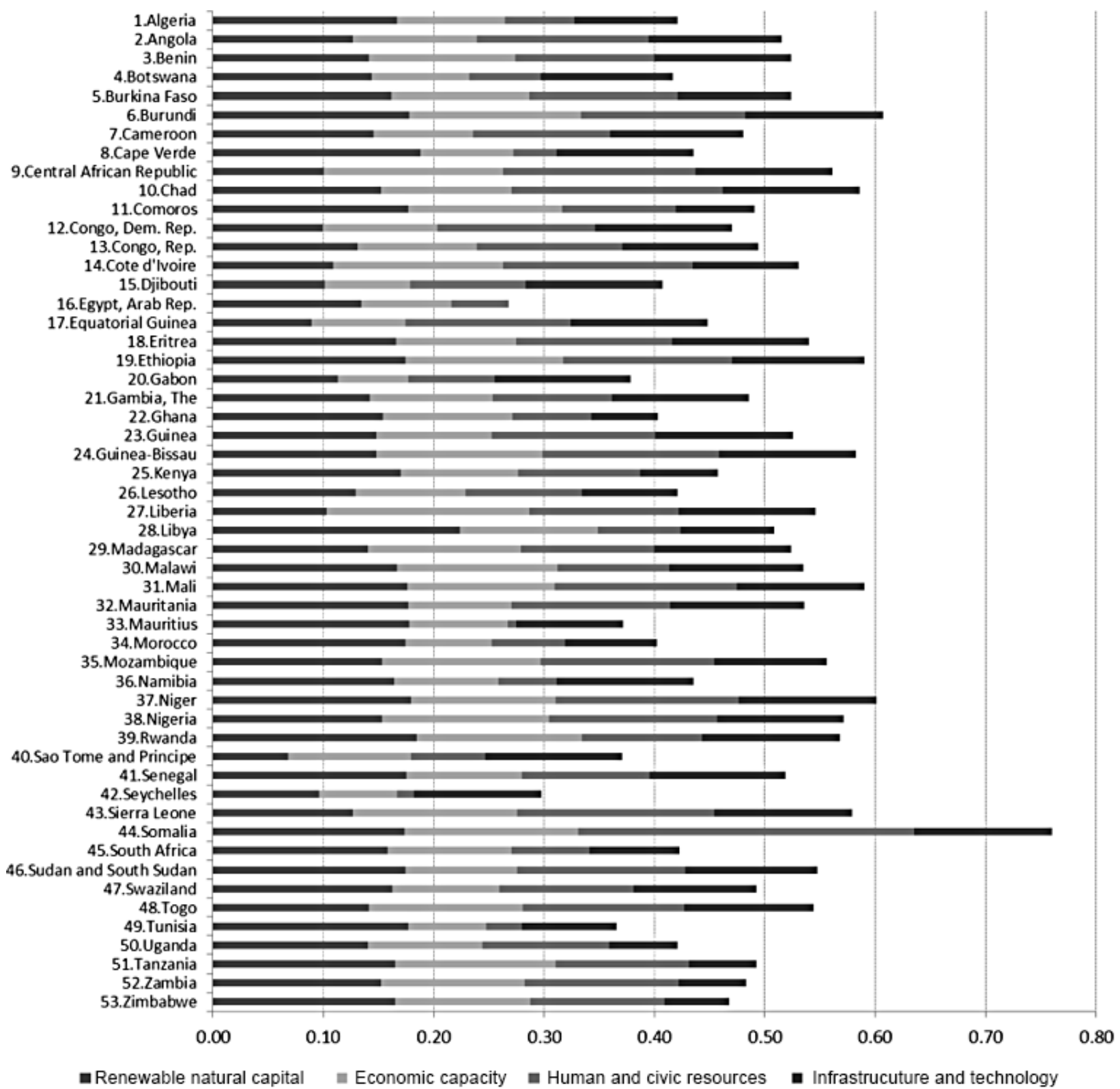

Fig. 7. Drought vulnerability index (DVI) disaggregated into their four components: renewable natural capital, economic capacity, human and civic resources, and infrastructure and technology. Countries are ordered by alphabetical order.

reported more than 1 million people affected in this period (e.g Somalia, Mali and Angola) are classified as having moderate to high vulnerability according to the DVI. On the other hand, three exceptions to this agreement are Ghana, Kenya, and Tanzania, where more than 10 million people affected were reported during the 1970-2006 period, but are classified as having vulnerabilities between low and moderate according to DVI. This could be due to the fact that there is a high spatial variability of the renewable natural component of vulnerability, as shown in the pixel and sub-basin level analysis. In fact, there are pixels with a high vulnerability to drought in some areas of these countries in contrast with other areas that show low vulnerability to drought (see Fig. 2).

Table 3 shows the contingency tables and tetrachoric coefficients between the dichotomised PRA and DVI variables. Although this result shows a significant direct relation (with a $95 \%$ confidence interval) between the DVI and the drought disasters, the amount of information in the database is not enough to display conclusive results since it does not include all the drought events. This correlation indicates that the behaviour of both variables is similar but it is not possible to use this correlation as a causality analysis between variables. 


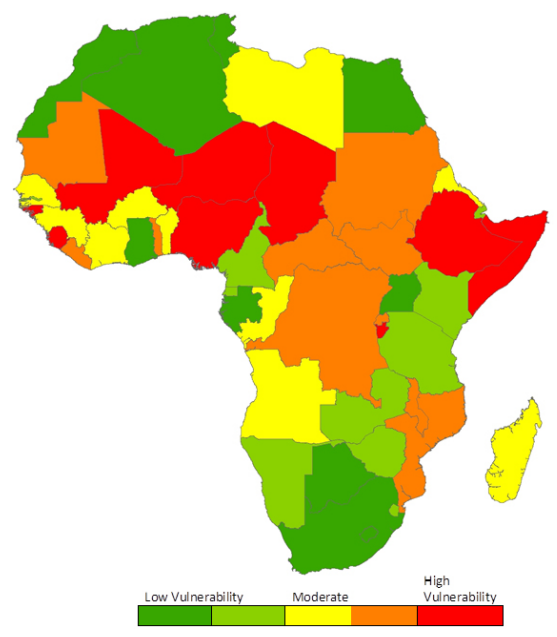

Fig. 8. Drought vulnerability index (DVI). The different levels of vulnerability were classified by dividing the sample in quintiles.

\section{Conclusions}

An indicator that estimates social vulnerability to drought (DVI) was developed and calculated at the Pan-African level. The methodology is appropriate to integrate both quantitative and qualitative characterisations of drought vulnerability at different spatial scales. The intermediate components of the DVI can be evaluated independently, allowing comprehensive interpretation of the strengths and weaknesses of each component.

Although the first results show that the DVI indicator developed can be used to evaluate countries' drought vulnerability, there are some limitations. First, our sample of selected components covers only some aspects of drought vulnerability in Africa. Second, our list of proposed variables that represent these components does not capture the full range of possible vulnerabilities and vulnerable groups to be included in early warning systems, particularly since it does not completely evaluate social conditions nor the response of stakeholder groups or market aspects. Third, our drought vulnerability index is estimated as a weighted average of these simple components assuming strong and well-defined relationships among the variables, which could be an interesting topic to discuss in further research. Additionally, in the context of the development of drought policy, the dynamics of the variables is not considered (i.e. climate change, population growth).

Moreover, the resolution and quality of the input data determines the accuracy and relevance of the derived information. Data available across the entire African continent was used, which usually is only available at national level. This will mask disparities within a country and as such can result in some discrepancies between other drought information data sets. More detailed and better quality data sets would

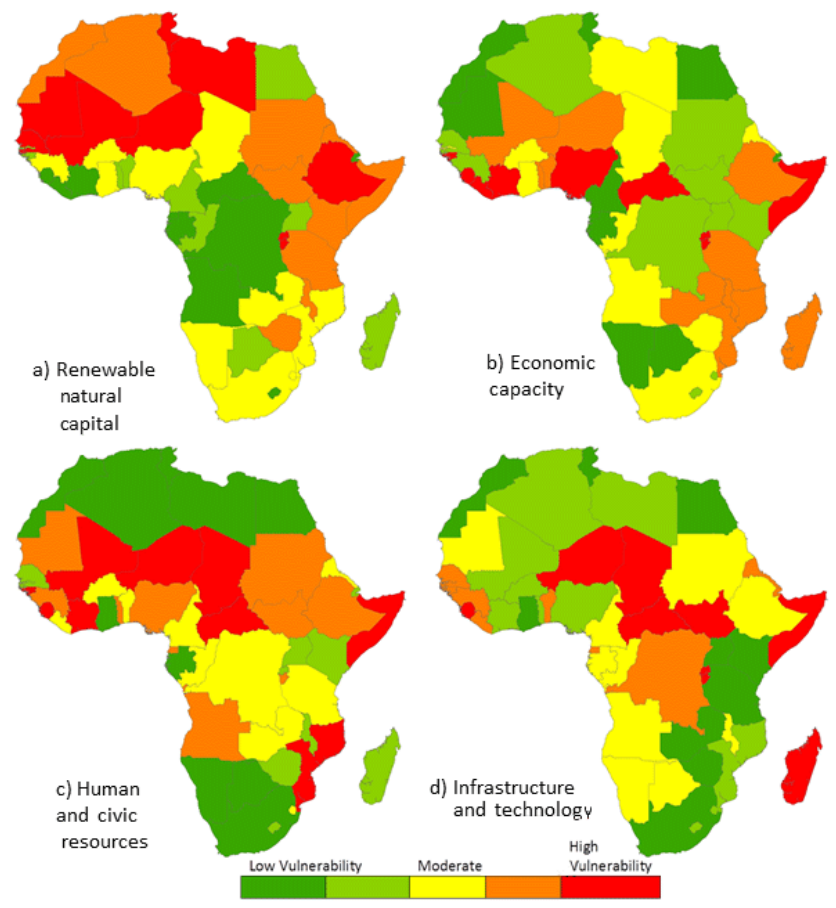

Fig. 9. Four components of the drought vulnerability index (DVI); (a) Renewable Natural Capital, (b) Economic Capacity, (c) Human and Civic Resources and (d) Infrastructure and Technology. The different levels of vulnerability were classified by dividing the sample in quintiles.

Table 3. Contingency tables and tetrachoric coefficient $\left(r_{t}\right)$ for the number of persons reported affected (PRA) by drought disasters and DVI. The analysis was performed over the 47 African countries with disaster data. Source: EM-DAT: the OFDA/CRED International Disaster Database - www.emdat.be, Université Catholique de Louvain, Brussels (Belgium).

\begin{tabular}{lrr}
\hline & Low DVI & High DVI \\
\hline Low no. persons reported affected & 16 & 7 \\
High no. persons reported affected & 7 & 17 \\
\hline \multicolumn{3}{c}{$r_{\mathrm{t}}=0.593 \sigma_{\mathrm{rt}}=0.1688$} \\
\end{tabular}

allow performing a more complete and accurate identification of drought vulnerability hotspots at sub-national level.

Despite these limitations, the analysis advances our knowledge of drought vulnerability in Africa by providing increased comprehension of the variety of reasons behind vulnerability and their relationship in a geographically and socially diverse continent.

The drought vulnerability indicator constructed using socio-economic data at country level explores some of the complex processes that could lead to social drought vulnerability. However, it must be used critically, taking into account that its construction relies on some subjective level of expert knowledge and theoretical assumptions. According to 
this analysis, the countries classified with higher relative vulnerability are Somalia, Mali, Ethiopia, Niger, Burundi and Chad.

The analysis of the renewable natural capital component of drought vulnerability at pixel level, and then aggregated at sub-basin level, shows that the basins with high to moderate drought vulnerability can be subdivided into three main different geographical regions: the Mediterranean coast of Africa (comprising most of the Moroccan and Algerian basins and the Nile Delta); the Sub-Sahara and the southern Sahel regions (including the Volta, Niger, White and Blue Nile and the Great Horn of Africa); the Serengeti and the Eastern Miombo woodlands of Tanzania and Mozambique. Additionally, the western part of the Zambezi Basin, the southeastern border of the Congo Basin and the belt of Fynbos in the Western Cape should also be included in this category.

Even if a cause-effect relationship cannot be established between the DVI and the drought disaster database, a good agreement is observed between the drought vulnerability maps and the number of persons affected by droughts. There is still a need to further validate the vulnerability indicator with more detailed drought impacts data in order to measure and improve their robustness and explain why in some cases extreme droughts can lead to disasters, while in other cases their impact is much lower. Future research is also needed to further understand why some regions or social groups are more vulnerable than others.

Acknowledgements. This work was funded by the European Commission Seventh Framework Programme (EU FP7) in the framework of the Improved Drought Early Warning and Forecasting to Strengthen Preparedness and Adaptation to Droughts in Africa (DEWFORA) project under Grant Agreement 265454.

Edited by: M. Werner

\section{References}

Adger, W. N.: Vulnerability, Global Environ. Change, 16, 268-281, 2006.

Anderson, W. B., Zaitchik, B. F., Hain, C. R., Anderson, M. C., Yilmaz, M. T., Mecikalski, J., and Schultz, L.: Towards an integrated soil moisture drought monitor for East Africa, Hydrol. Earth Syst. Sci., 16, 2893-2913, doi:10.5194/hess-16-28932012, 2012.

Arrow, K. J.: Social choice and individual values, 2nd Edn., Wiley, New York, 1963.

Birkmann, J.: Risk and vulnerability indicators at different scales: applicability, usefulness and policy implications, Environ. Hazards, 7, 20-31, 2007.

Brooks, N., Neil Adger, W., and Mick Kelly, P.: The determinants of vulnerability and adaptive capacity at the national level and the implications for adaptation, Global Environ. Change, 15, 151$163,2005$.
Burke, M. B., Miguel, E., Satyanath, S., Dykema, J. A., and Lobell, D. B.: Warming increases the risk of civil war in Africa, Proc. Natl. Acad. Sci., 106, 20670-20674, 2009.

Charusombat, U. and Niyogi, D.: A hydroclimatological assessment of regional drought vulnerability: A case study of Indiana droughts, Earth Inter., 15, 1-65, 2011.

Cherchye, L., Moesen, W., Rogge, N., Van Puyenbroeck, T., Saisana, M., Saltelli, A., Liska R., and Tarantola, S.: Creating composite indicators with DEA and robustness analysis: the case of the technology achievement index, J. Operat. Res. Soc., 59, 239-251, 2007.

Christensen, J. H., Hewitson, B., Busuioc, A., Chen, A., Gao, X., Held, I., Jones, R., Kolli, R. K., Kwon, W.-T., Laprise, R., Magaña Rueda, V., Mearns, L., Menéndez, C. G., Räisänen, J., Rinke, A., Sarr, A., and Whetton, P.: Regional Climate Projections, in: Climate Change 2007: The Physical Science Basis, Contribution of Working Group I to the Fourth Assessment Report of the Intergovernmental Panel on Climate Change, edited by: Solomon, S., Qin, D., Manning, M., Chen, Z., Marquis, M., Averyt, K. B., Tignor, M., and Miller, H. L., Cambridge University Press, Cambridge, United Kingdom and New York, NY, USA, 2007.

Drasgow, F.: Polychoric and polyserial correlations, in: Encyclopedia of statistical sciences, edited by: Kotz, S., Johnson, N. I., and Read, C. B., Vol. 7, 68-74, New York: Wiley, 1986.

Dutra, E., Di Giuseppe, F., Wetterhall, F., and Pappenberger, F.: Seasonal forecasts of droughts in African basins using the Standardized Precipitation Index, Hydrol. Earth Syst. Sci., 17, 23592373, doi:10.5194/hess-17-2359-2013, 2013.

Dutra, E., Pozzi, W., Wetterhall, F., Di Giuseppe, F., Magnusson, L., Naumann, G., Barbosa, P., Vogt, J., and Pappenberger, F.: Global meteorological drought - Part 2: Seasonal forecasts, Hydrol. Earth Syst. Sci. Discuss., 11, 919-944, doi:10.5194/hessd11-919-2014, 2014.

Eriksen, S. H. and O'Brien, K.: Vulnerability, poverty and the need for sustainable adaptation measures, Climate Pol., 7, 337-352, 2007.

Eriksen, S. H., Brown, K., and Kelly, P. M.: The dynamics of vulnerability: locating coping strategies in Kenya and Tanzania, The Geographical J., 171, 287-305, 2005.

FAO: The State of Food Insecurity in the World 2010: Addressing Food Insecurity in Protracted Crises, Rome, 2010.

Füssel, H. M.: Vulnerability: a generally applicable conceptual framework for climate change research, Global Environ. Change, 17, 155-167, 2007.

Hartigan, J. A. and Wong, M. A.: A K-means clustering algorithm, Appl. Stat., 28, 100-108, 1979.

Hsiang, S. M., Burke, M., and Miguel, E.: Quantifying the influence of climate on human conflict, Science, 341, 1235367, doi:10.1126/science.1235367, 2013.

Iglesias, A., Garrote, L., Flores, F., and Moneo, M.: Challenges to manage the risk of water scarcity and climate change in the Mediterranean, Water Resour. Manage., 21, 775-788, 2007.

Iglesias, A., Garrote, L., Cancelliere, A., Cubillo, F., and Wilhite, D. A.: Coping with drought risk in agriculture and water supply systems, in: Drought management and policy development in the Mediterranean, series: advances in natural and technological hazards research, 26, 322 p., 2009. 
Leichenko, R. M. and O'Brien, K. L.: The dynamics of rural vulnerability to global change: the case of southern Africa, Mitig. Adapt. Strat. Global Change, 7, 1-18, 2002.

Little, R. J. A. and Rubin, D. B.: Statistical Analysis with Missing Data (Wiley Series in Probability and Statistics), WileyInterscience, p. 408, 2002.

Luers, A. L., Lobell, D. B., Sklar, L. S., Addams, C. L., and Matson, P. A.: A method for quantifying vulnerability, applied to the agricultural system of the Yaqui Valley, Mexico, Global Environ. Change, 13, 255-267, 2003.

Nardo, M., Saisana, M., Saltelli, A., Tarantola, S., Hoffman, A., and Giovannini, E.: Handbook on constructing composite indicators: methodology and user guide (No. 2005/3), OECD publishing, 2005.

Nelson, R., Howden, M., and Smith, M. S.: Using adaptive governance to rethink the way science supports Australian drought policy, Environ. Sci. Pol., 11, 588-601, 2008.

Neumayer, E.: The human development index and sustainability a constructive proposal, Ecol. Econom., 39.1, 101-114, 2001.

Saisana, M., Saltelli, A., and Tarantola, S.: Uncertainty and sensitivity analysis techniques as tools for the quality assessment of composite indicators, J. Roy. Stat. Soc. A, 168, 307-323, 2005.

Schneider, U., Becker, A., Finger, P., Meyer-Christoffer, A., Ziese, M., and Rudolf, B.: GPCC's new land surface precipitation climatology based on quality-controlled in situ data and its role in quantifying the global water cycle, Theor. Appl. Climatol., 115, 1-26, doi:10.1007/s00704-013-0860-x, 2013.

Shiau, J. T. and Hsiao, Y. Y.: Water-deficit-based drought risk assessments in Taiwan, Nat. Hazards, 64, 237-257, 2012.

Smit, B., Burton, I., Klein, R. J., and Street, R.: The science of adaptation: a framework for assessment, Mitig. Adapt. Strat. Global Change, 4, 199-213, 1999.

Taylor, I. H., Burke, E., McColl, L., Falloon, P. D., Harris, G. R., and McNeall, D.: The impact of climate mitigation on projections of future drought, Hydrol. Earth Syst. Sci., 17, 2339-2358, doi:10.5194/hess-17-2339-2013, 2013.

Turner, B. L., Matson, P. A., McCarthy, J. J., Corell, R. W., Christensen, L., Eckley, N., Hovelsrud-Broda, G., Kasperson, J., Kasperson G., Luers, A., Martello, M., Mathiesen, S., Naylor, R., Polsky, C., Pulsipher, A., Schiller, A., Selin, H., and Tyler, N.: Illustrating the coupled human-environment system for vulnerability analysis: three case studies, Proc. Natl. Acad. Sci., 100, 8080-8085, 2005.
UNISDR: United Nations International Strategy for Disaster Reduction, United Nations, United Nations, Geneva, 2000.

van Huijgevoort, M. H. J., Hazenberg, P., van Lanen, H. A. J., and Uijlenhoet, R.: A generic method for hydrological drought identification across different climate regions, Hydrol. Earth Syst. Sci., 16, 2437-2451, doi:10.5194/hess-16-2437-2012, 2012.

Van Lanen, H. A. J., Wanders, N., Tallaksen, L. M., and Van Loon, A. F.: Hydrological drought across the world: impact of climate and physical catchment structure, Hydrol. Earth Syst. Sci., 17, 1715-1732, doi:10.5194/hess-17-1715-2013, 2013.

Van Loon, A. F. and Van Lanen, H. A. J.: A process-based typology of hydrological drought, Hydrol. Earth Syst. Sci., 16, 19151946, doi:10.5194/hess-16-1915-2012, 2012.

Vicente-Serrano, S. M., Beguería, S., Gimeno, L., Eklundh, L., Giuliani, G., Weston, D., El Kenawy, A., López-Moreno, J., Nieto, R., Ayenew, T., Konte, D., Ardö, J., and Pegram, G. G.: Challenges for drought mitigation in Africa: The potential use of geospatial data and drought information systems, Appl. Geogr., 34, 471-486, 2012.

Vörösmarty, C. J., Green, P., Salisbury, J., and Lammers, R.: Global water resources: Vulnerability from climate change and population growth, Science, 289, 284-288, 2000.

Vörösmarty, C. J., Douglas, E. M., Green, P. A., and Revenga, C.: Geospatial indicators of emerging water stress: an application to Africa, AMBIO: A journal of the Human Environment, 34, 230 236, 2005.

Welsh, L. W., Endter-Wada, J., Downard, R., and Kettenring, K. M.: Developing adaptive capacity to droughts: the rationality of locality, Ecol. Soc., 18, 7-16, doi:10.5751/ES-05484-180207, 2013.

Westing, A. H.: Environmental refugees: a growing category of displaced persons, Environ. Conserv., 19, 201-207, 1992.

Wilhelmi, O. V. and Wilhite, D. A.: Assessing vulnerability to agricultural drought: a Nebraska case study, Nat. Hazards, 25, 37-58, 2002. 